\title{
ОЦЕНКА СООРУЖЕНИЙ ИНЖЕНЕРНОЙ ЗАЩИТЫ, СИСТЕМ ВОДОСНАБЖЕНИЯ И ВОДООТВЕДЕНИЯ СРЕДСТВАМИ ДИСТАНЦИОННОЙ ДИАГНОСТИКИ
}

\author{
В. Е. Левкевич ${ }^{1}$, А. В. Бузук ${ }^{2}$, В. А. Лосицкий ${ }^{3}$ \\ В. А. Мильман ${ }^{4}$, С. В. Решетник \\ 1 Д. т. н., профрессор, профрессор кафредры «Водоснабжение и водоотведение» \\ учреждения образования «Белорусский национальный технический университет», Минск, Беларусь, e-mail: eco2014@tut.by \\ 2 Преподаватель Университета гражданской защиты МЧС Республики Беларусь, Минск, Беларусь, e-mail: uk007@rambler.ru \\ ${ }_{3}^{3}$ Магистр технических наук, старший преподаватель кафедры «Строительство и эксплуатация зданий и сооружений» \\ Филиала БНТУ МИПКиПК; аспирант кафредры «Водоснабжение и водоотведение» \\ учреждения образования «БНТУ», Минск, Беларусь, e-mail: losickiy1993@gmail.com \\ 4 Зав. сектором Объединенного института проблем информатики (ОИПИ) НАН Беларуси, Минск, Беларусь, е-mail: victormi29@mail.ru \\ 5 Главный конструктор проекта Объединенного института \\ проблем инфоорматики (ОИПИ) НАН Беларуси, Минск, Беларусь, e-mail: rsvlad@tut.by \\ ${ }^{6}$ Аспирант кафредры «Водоснабжение и водоотведение» учреждения образования \\ «Белорусский национальный технический университет», Минск, Беларусь, e-mail: faromuzsaidov95@gmail.com
}

\section{Ресрерат}

Как известно водохранилища представляют собой сложные природнотехнические комплексы. Создаваемые водные объекты наряду с положительным эффектом оказывают отрицательное воздействие на окружающую природную среду. Наиболее опасные проявления этого: абразия - переработка естественных берегов и незакрепленных верховых грунтовых откосов дамб и плотин, подтопление и заболачивание территорий. В результате развития указанных отрицательных процессов происходит изъятие сельскохозяйственных земель и лесных угодий из оборота, разрушение селитебных территорий, нарушение условий жизнедеятельности населения - это осложняет условия эксплуатации водозаборов (в том числе и поверхностных), а также эксплуатации очистных сооружений, что приносит значительный ущерб народному хозяйству государства. Основой безопасной жизнедеятельности населения, проживающего непосредственно рядом с водохранилищами, и нормальной эксплуатации инженерных сооружений является достоверная оценка состояния сооружений берегозащиты и объектов экономики, к которым относятся также системы водоснабжения и водоотведения селитебных территорий.

В настоящей статье приведены некоторые результаты исследований по оценке состояния эксплуатируемых сооружений берегозащиты на водохранилищах, водозаборов, очистных сооружений, находящихся в прибрежной зоне водных объектов с помощью средств дистанционной диагностики. На основе анализа и опыта использования современных технологий обработки спутниковой информации, методов и средств дистанционной диагностики - беспилотных летательных аппаратов (БПЛА) даны некоторые концептуальные предложения по ведению мониторинга водохозяйственных объектов.

Ключевые слова: водохранилища, абразивный процесс, берегозащита, дистанционная диагностика, беспилотный летательный аппарат.

\section{ASSESSMENT OF ENGINEERING PROTECTION STRUCTURES, WATER SUPPLY AND SANITATION SYSTEMS BY MEANS OF REMOTE DIAGNOSTICS}

Abstract

The article presents some research results on assessing the status of operating shore protection facilities in reservoirs, water intakes, treatment facilities located in the coastal zone of water bodies using remote diagnostics. Based on the analysis and experience of using modern technologies for processing satellite information, methods and means of remote diagnostics - unmanned aerial vehicles, some conceptual proposals for monitoring water facilities are given.

Keywords: reservoirs, abrasive process, coastal protection, remote diagnostics, unmanned aeriel vehicle.

\section{Введение}

Водохранилища представляют собой сложные природно-технические комплексы. Создаваемые на базе рек, озер водные объекты наряду с положительным эффектом оказывают отрицательное воздействие на окружающую природную среду. Наиболее опасные проявления этого: абразия - переработка естественных берегов и незакрепленных верховых грунтовых откосов дамб и плотин, подтопление и заболачивание территорий. В результате развития указанных отрицательных процессов происходит изъятие сельскохозяйственных земель и лесных угодий из оборота, разрушение селитебных территорий, нарушение условий жизнедеятельности населения - это осложняет условия эксплуатации водозаборов (в том числе и поверхностных), а также эксплуатации очистных сооружений - что приносит значительный ущерб народному хозяйству государства. Основой безопасной жизнедеятельности населения, проживающего непосредственно рядом с водохранилищами, и нормальной эксплуатации инженерных сооружений является достоверная оценка состояния сооружений берегозащиты и объектов экономики, к которым относятся также системы водоснабжения и водоотведения селитебных территорий.

Как известно, с созданием нового водохранилища происходит активное формирование его береговой зоны под воздействием различных гидродинамических факторов: ветрового волнения, колебания уровней, течений, ледовых явлений. Развитие береговых процессов, в частности переработки берегов, имеет масштабы, которые непосредственно угрожают хозяйственным объектам, населенным пунктам и прилегающим территориям. В зоне активного берегоформирования оказываются водозаборы, гидротехнические сооружения, жилые постройки, очистные сооружения, дороги, линии электропередач, а также объекты берегозащиты.

В настоящей работе, приведены некоторые результаты исследований, целью которых явились: 
Вестник Брестского государственного технического университета. 2021

- разработка предложений по мониторингу деформаций берегов, состоянию ограждающих сооружений водных объектов, водозаборов и очистных сооружений на основе данных дистанционного зондирования;

- оценка возможности комплексного использования технологии и применения систем обработки космических и авиационных снимков, а также сведений беспилотных летательных аппаратов (БПЛА) и наземных съемок для решения задач мониторинга природных процессов и прикладных задач, связанных с эксплуатацией сооружений.

Основная часть. Натурное обследования методами дистанционной диагностики

Комплексное натурное обследование ряда водохранилищ Беларуси (более 100 единиц) и сооружений на них с помощью беспилотных летательных аппаратов (БПЛА), проводимых специалистами Белорусского национального технического университета и Объединенного института проблем информатики НАН Беларуси и наземных съемок, позволило установить нарушения в состоянии и дефекть инженерной защиты берегов водохранилищ, креплений откосов дамб и плотин, а также эксплуатации водозаборов, водовыпусков и самих очистных сооружений, последние связанные с заилением и занесением песчаным материалом оголовков, возникающим в результате вдольберегового перемещения наносов в прибрежной зоне водохранилищ [1-5].

Применение традиционных наземных методов исследований и наблюдений является по характеру получаемой информации дискретной технологией, которая ограничивается сбором информации через достаточно большие интервалы времени. Поэтому в настоящее время практика показала при ведении комплексных мониторинговых наблюдений и съемок площадного объекта (водохранилища, озера, пруда, водохозяйственного объекта) целесообразно использовать дистанционные методы, отображающие динамику процессов, происходящих в прибрежной зоне на различных стадиях развития в сочетании с наземными. Повторные измерения, выполняемые через эквидистантные временные интервалы или по выбранным событиям, позволяют получить пространственно-временную характеристику того или иного процесса. За счет последовательного накопления данных об элементарном процессе по некоторым участкам побережья могут быть сделаны выводы как о динамике процесса в целом, так и о тенденциях его развития под влиянием внешних воздействующих фракторов и условий [1-7].

Использование дистанционных средств обеспечивает одновременную (в расчете на масштаб процесса) съемку большого района береговой зоны и контроль ее состояния (размер поля съемки в несколько квадратных километров) при небольшом временном смещении. Для некоторого момента времени эта технология обеспечивает возможность выявления пространственной связи морфологических, гидродинамических и гидрологических условий, характерных для объекта наблюдений.

Этот метод хорошо удовлетворяет требованиям охраны окружающей среды и водного хозяйства в прибрежных районах. На основе высокого информационного содержания материалов космической съемки возможно как топографическое, так и тематическое картирование прибрежных территорий, для этого достаточны использовать космические снимки, получаемые, например МКС с высоты около 250 км (масштаб оригинала М 1:2 000 000) в четырех спектральных диапазонах видимого излучения (от 460 до 680 нм) имеют разрешение по поверхности Земли равное около 10 м для линейных объектов. Многозональные аэроснимки в масштабе 1:50000 с высокой точностью могут быть использованы для обновления топографических карт в масштабе 1:10000. Вследствие высокой метрической точности многозональные снимки можно относительно просто совмещать с существующими картами. Таким образом, имеется возможность постоянного обновления различных серий карт и баз данных (например, базы данных кадастра берегов).

Результаты тематической обработки космических или аэроффотоснимков могут использоваться для исследований в интересах водного хозяйства, геологии и инженерной защиты территорий при оценке интенсивности отступания береговой линии (рисунок 1) $[6,7]$.

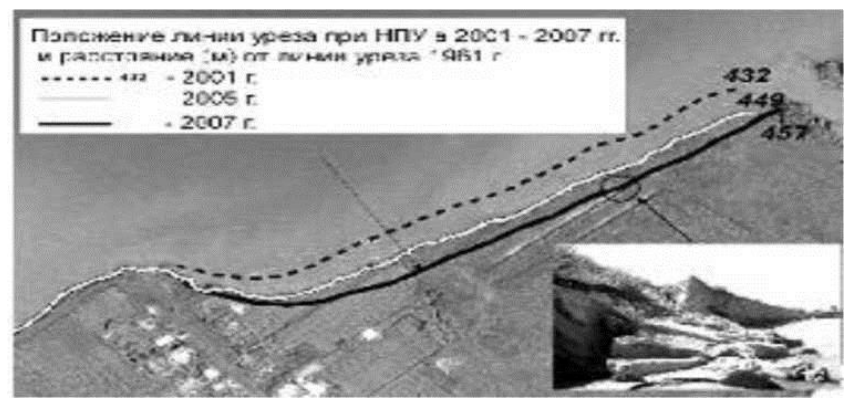

Рисунок 1 - Новосибирское водохранилище, правый берег. Отступание берега в результате переработки (2001-2007 гг.) и разрушение берегоукрепления. Снимок со спутника lkonos $[6,7]$

Второй, не менее важной, задачей в исследованиях явилось сравнение точности методов дистанционного зондирования и стандартных наземных методов измерений в гидротехническом и водохозяйственном строительстве. Также проводилось тематическое геоморфологическое дешифрирование фотоснимков для создания схем формирования берегов так называемых тестовых водохранилищ. В качестве тестовых водоемов для изучения были выбраны четыре водохранилища Минской области, по которым в течение ряда лет проводятся стационарные комплексные наблюдения за динамикой береговых процессов. К этим водохранилищам относятся: Заславское, Криницы, Вяча и Дубровское [1,2]. Аналогичная работа выполнена по Горьковскому водохранилищу России [5] (рисунок 2).

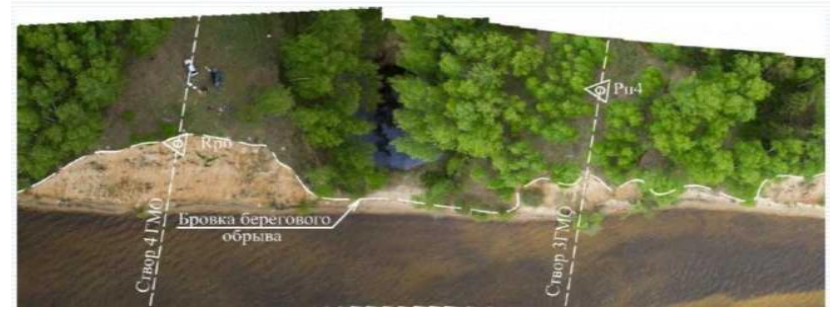

Рисунок 2 - Аэрофоотосъемка левого берега Горьковского водохранилища [5]

Проведение синхронных аэро- и наземных съемок в квазистационарном временном режиме (практически в реальном режиме времени) с синхронизацией до 5 часов позволило по конкретным участкам береговой линии водоемов и створам оценить сопоставимость и точность используемых методик. В качестве параметров дешифрирования материалов аэрофотосъемок использовался ряд специфических дешифровочных признаков [4, 7]: ширина надводной и подводной частей литоральной зоны тестовых водохранилищ; ширина надводной зоны, подверженной десрормациям; цвет и плотность изображения донных отложений и размываемого грунта коренных береговых склонов; форма и плановые очертания аккумулятивных и абразионных участков береговой линии; соотношение протяженностей берегов различного типа; коэффициенты извилистости, изрезанности и развития береговой линии тестовых водоемов; коэффициент формы водоемов в плане.

Идентификаторами береговых процессов являлось наличие на фотографиях береговой зоны водохранилищ на границе водаматерик репрезентативных участков светлого и полусветлого тонов, которые соответствуют надводной и подводной составляющим береговой отмели. Изменение полутонов, тонов и оттенков позволили идентифицировать зоны транзита наносов и их аккумуляции и накопления, а также поступления пляже образующего материала на береговую отмель. Участку поступления наносов соответствуют зоны волновой абразии, а в ряде случаев - поверхностной эрозии. Как правило, в условиях водохранилищ фрагментам береговой линии, на которых проявляются абразионные 
процессы, соответствуют и формы рельефра, где возможно развитие процесса поверхностной эрозии, проявляющейся в виде оврагов, балок, эрозионных канав, подтопления и заболачивания территории и т. д.

При мониторинге берегов, равно как и мониторинге водозаборов и очистных сооружений, находящихся в прибрежной зоне водоемов, выступают определенные репрезентативные участки прибрежной и береговой территории. При выборе характерных, репрезентативных участков побережья учитываются геологические, морфологические и гидрологические особенности береговых склонов. Причем, в случае выбора участков наблюдений применялся предложенный нами комплексный критерий однородности выборки контрольных створов [1, 2], структура которого приведена ниже:

\section{$\mathbf{P}_{\mathbf{T}}=\{$ Тип $[$ Подтип (Форма склона $\left.)]\right\}$,}

где Рт - комплексный безразмерной критерий, позволяющий учитывать пространственную однородность фрагментов участков береговой линии, необходимую при проведении сравнительного анализа объектов мониторинга. Например: Тип - абразионный, аккумулятивный, нейтральный и т. д.; Подтип - абразионно-обвальный, абразионно-осыпной, абразионно-оползневой и т. д.; Форма склона - обрывистый, пологий и т. д.

Практика наблюдений показала, что при ведении наземных наблюдений следует разбивать и закладывать контрольные участки в различных зонах водоема: низовой или приплотинной, средней и верховой. Протяженность участков может быть различная. Количество створов наблюдений, по которым проводится разбивка поперечников, в зависимости от протяженности контрольного участка, который колеблется от одного (участок длиной не более $50 \mathrm{~m}$ ) до 15 единиц. Расстояние между поперечниками, как показала практика ведения наблюдений, может составлять от 25 до 50 м. Плановая съемка осуществляется при помощи стандартного оборудования: теодолитов, теодолитов-нивелиров с последующей привязкой к существующим реперам государственной триангуляционной сети при помощи разбивки теодолитных ходов и станций наземного позиционирования типа Wild GPS и других комплектов аналогичного оборудования [2].

В случае дополнения мониторинговых наблюдений средствами дистанционной диагностики съемка береговой линии и участков в местах расположения водозаборов или очистных сооружений проводятся по участкам, на которых ранее велись или ведутся наблюдения по наземной сети, закрепленной к соответствующим временным или постоянным реперам. Отметки поверхности склонов принимаются в увязке с отметками водного зеркала. Масштабы маршрутных аэрофоотосъемок могут составлять от 1:5000 до 1:6000.

Опытным путем было установлено, что наилучшим периодом проведения наблюдений является весна или же период пред ледоставный (октябрь - ноябрь месяцы). Аэрофотосъемку следует проводить в апреле - июне месяце. После проведения полевых изысканий производится камеральная обработка полученных данных, лабораторный анализ отобранных проб и образцов и анализ полученной информации о масштабах и динамике береговых процессов. Информация по каждому объекту подготавливается для ее последующего переноса в базы данных.

Получаемая в результате мониторинговых съемок наземной и дистанционной информация после обработки может быть представлена в виде обобщенных таблиц с перечнем основных эксплуатационных, морфологических, гидрологических и прочих характеристик и показателей, т. е. материалов общего плана, а также специальных чисто мониторинговых показателей - параметров береговой линии водных объектов, их динамика, масштабы, интенсивность и т. д. Сопоставление вышеупомянутых сведений, подтвержденных цифрровой информацией, позволяет отслеживать динамику всех процессов, корректировать текущие кратко- (от 2 до 5 лет) и долгосрочные (от 10 до 25 лет) прогнозы и производить корректировку ретроспективных прогнозов с учетом техногенного воздействия на береговую линию. Этот подход используется и наблюдений за берегоукрепительными и очистными сооружениями и водозаборами.
В настоящее время известны различные типы информационных систем в области береговой гидротехники. Программные продукты для расчета параметров динамики береговой зоны водохранилищ создаются в различных организациях России, Беларуси, Украины. Например, Институт океанологии РАН (г. Москва) совместно с Институтом водных и экологических проблем СО РАН (г. Барнаул) разработали на сегодняшний день наиболее простой и эфффективный программный продукт, позволяющий выполнять расчеты деформации профиля, расчеты переноса наносов, прогнозировать береговые процессы волновой природы с учетом разработанных моделей развития берегов крупных водохранилищ $[8,9]$. Для условий Беларуси была разработана предметно-ориентированная база данных (БД) искусственных водных объектов Беларуси. БД предназначена для повышения эффрективности контроля (надзора) за техническим состоянием гидротехнических сооружений на объектах водохранилищного фонда Беларуси и оперативного реагирования на чрезвычайные ситуации данной категории. БД позволяет автоматизировать процесс оценки обстановки для принятия управленческого решения $[4,5]$. База данных построена по многокомпонентной архитектуре и включает:

- базовый компонент данных (зашит в листы и хранит всю информацию о базе в информационных блоках);

- блоки информации (папки с данными), которые являются вспомогательными элементами при отображении запрашиваемой информации;

База данных обеспечивает возможность корректировки (актуализации) текстовой информации при эксплуатации. Существует возможность вывода информации в текстовые файлы и распечатки информации на принтер. Ввод и вывод информации осуществляется пользователем путем вызова контекстного меню с выбором требуемого действия из перечня.

Кроме стандартных методик для сплошной съемки территории предлагается широко использовать возможности дистанционных методов с применением средств авиационного и космического базирования. В настоящее время технически возможно использовать для этой цели существующий Белорусский космический аппарат.

Для совместного анализа пространственно-распределенных данных используются геоинформационные системы (ГИС). ГИС являются основой для формирования других информационных систем, также работающих с пространственно-распределенными данными. ГИС объединяют картографические материалы в растровом и векторном виде, а также семантическую информацию по объектам картографирования в виде базы данных. Можно использовать как оригинальные продукты типа Map Info, Arc View и ряд других, а также оригинальные разработки белорусских разработчиков ОИПИ НАН Беларуси (рисунок 3).

Картографическая основа любой ГИС-системы, как правило, состоит из цифровых топографических карт и планов различных районов республики, населенных пунктов. На цифровые картографические материалы наносятся тематические слои [3, 4].

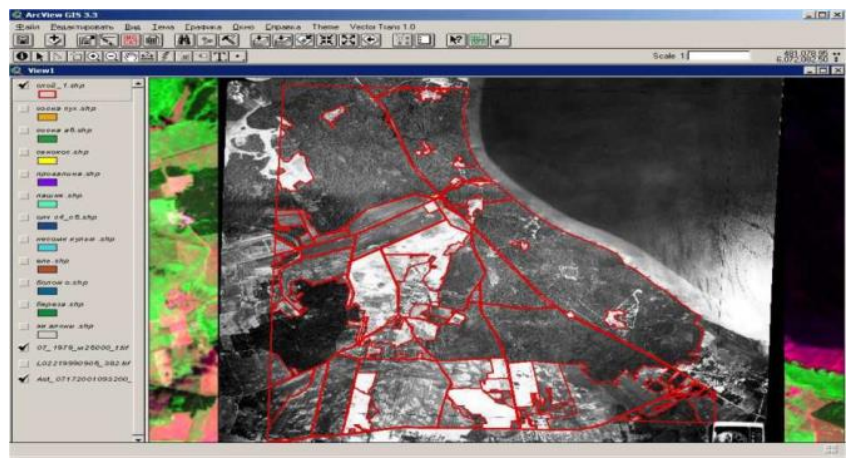

Рисунок 3 - Интерфейс ГИС Arc View с аэрофоотоснимком береговой зоны водохранилища 
Вестник Брестского государственного технического университета. 2021

Важными преимуществами методов дистанционного зондирования Земли являются регулярность отслеживания состояния земной поверхности, большая обзорность, высокая оперативность получения информации об интересующем районе и интеграция полученных данных в геоинформационные системы. Генерализация деталей на изображениях Земли из Космоса обеспечивает исследования разных по охвату регионов и позволяет проследить за наиболее характерными процессами прохождения половодья по всей длине реки от истока до устья. При проведении космической съемки затопляемых территорий целесообразно использовать информацию различного пространственного разрешения в разных спектральных диапазонах [4]. Со снимков среднего разрешения (сенсоры МСУ-СК, Modis) можно извлекать полезную информацию о состоянии пойм рек. По снимкам высокого разрешения (сенсоры LISS, ASTER, MCУ-Э космических аппаратов серии Landsat) более точно определяется положение урезов воды и с большей достоверностью выделяются затопленные участки поймы. Съемка в микроволновом диапазоне (RADARSAT) дает возможность получать информацию о наводнениях независимо от освещенности и облачности.

На основе высокого информационного содержания материалов съемки возможно как топографическое, так и тематическое картирование в масштабах карт, используемых в народном хозяйстве. Космические снимки, получаемые современной многозональной фотоаппаратурой с высот около 250 км (масштаб оригинала M 1:2000 000) в четырех спектральных диапазонах видимого излучения (460-680 нм), имеют разрешение по поверхности Земли, равное около 10 м для линейных объектов. Аэроснимки в масштабе 1:50 000 с высокой точностью могут быть использованы для обновления топографических карт в масштабе 1:10 000 (рисунок 4).

Проведенные в последние годы натурные исследования водохранилищного фонда страны (2010-2020 гг.) позволили оценить состояние эксплуатации береговых водозаборов| дамб обвалования прудов очистных сооружений (рисунок 5).

В республике наиболее распространены поверхностные водозаборы раздельного и совмещенного типов (рисунок 4). Кроме того в стране существуют поверхностные водозаборы с «прямым отбором» воды для обеспечения рыбхозов, мелиоративных объектов, а также малых ГЭС. К таким сооружениям относятся водозаборы на водохранилищах: Любанское, Локтыши, Погост, Селец, Дубровское, Осиповичское и другие. Следует также отметить, что ряд водохранилищ наливного типа (Муровно, Локтыши, Любашевское, Ельское, Бальшие Орлы, Малые Автюки, Смолевичское и пр.) наполняемые насосными станциями $(\mathrm{HC})$ двойного действия: в весенний период они служат для наполнения водоема, в период межени - для орошения и обводнения и водоснабжения. Все конструкции НС служат в этом случае в качестве водозабора раздельного типа.

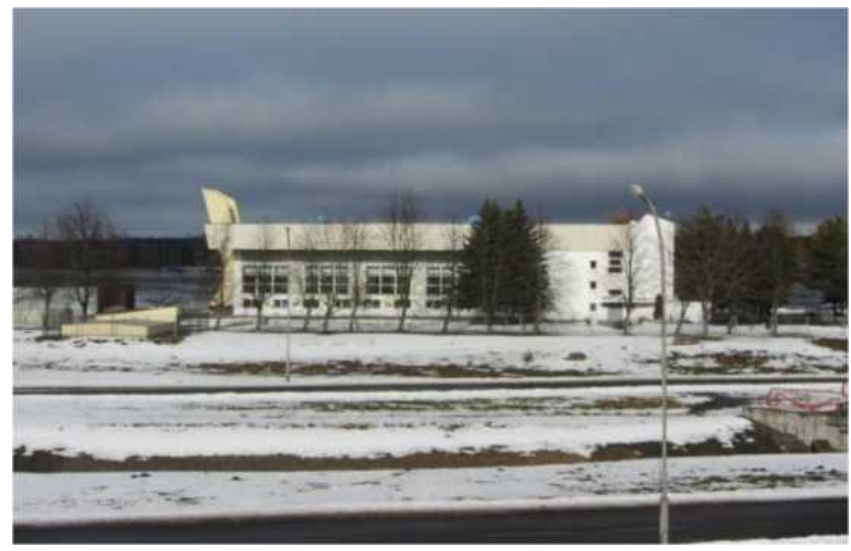

Рисунок 4 - Поверхностный водозабор на водохранилище Дрозды с прямым отбором воды

Обследование ряда объектов показало, что общее состояние конструкций и отдельных узлов водозаборных сооружений находятся в хорошем и удовлетворительном состоянии. В некоторых случаях наблюдается износ бетонных и металлических конструкций. Это касается коррозии сороудерживающих решеток и закладных деталей, нарушения целостности некоторых элементов бетонных конструкций, что связано с воздействием ветрового волнения и ледового покрова. Обследование водохранилищ и сооружений на них позволило установить нарушения в работе, связанные с заилением и занесением песчаным материалом, в результате вдоль берегового перемещения наносов в прибрежной зоне, образующегося в результате переработки берега.

Дистанционная диагностика с использованием космических аппаратов и современных БПЛА позволяет в значительной мере облегчить процесс мониторинга прибрежной зоны водохранилищ, а крупномасштабная съемка наиболее удобна для изучения состояния откосов сооружений, очистных сооружений и водозаборов (рисунок 5).
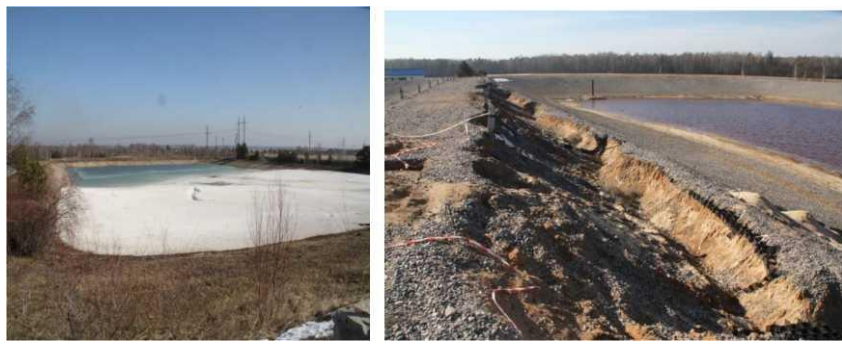

а) пруды накопителя; б) разрушение откосов ограждающей дамбы

\section{Рисунок 5 - Состояние ограждающих дамб очистных сооружений}

В безледный период 2019 г. была экспериментально апробирована методика регистрации деформации береговых склонов и оценки состояния дамб обвалования, их крепления, водозаборов и очистных сооружении с помощью современных средств - легких беспилотных летательных аппаратов (БПЛА) - квадрокоптеров. Использование радиоуправляемого квадрокоптера профессиональной серии позволило провести съемку с высоты до 70 м над уровнем воды. Используемый в экспериментах квадрокоптер модели DJI Phantom 3 Professional, оснащенный системой позиционирования GPS, акселерометром, датчиком высоты, 3-х осевым стабилизующим подвесом цветной видеокамеры 4K с разрешением 12 мегапикселей видеокамерой, позволяет передавать HD видео в онлайн-режиме и делать фотографии и видеозапись высокого разрешения. Внешний вид используемого квадрокоптера показан на рисунок 6 .

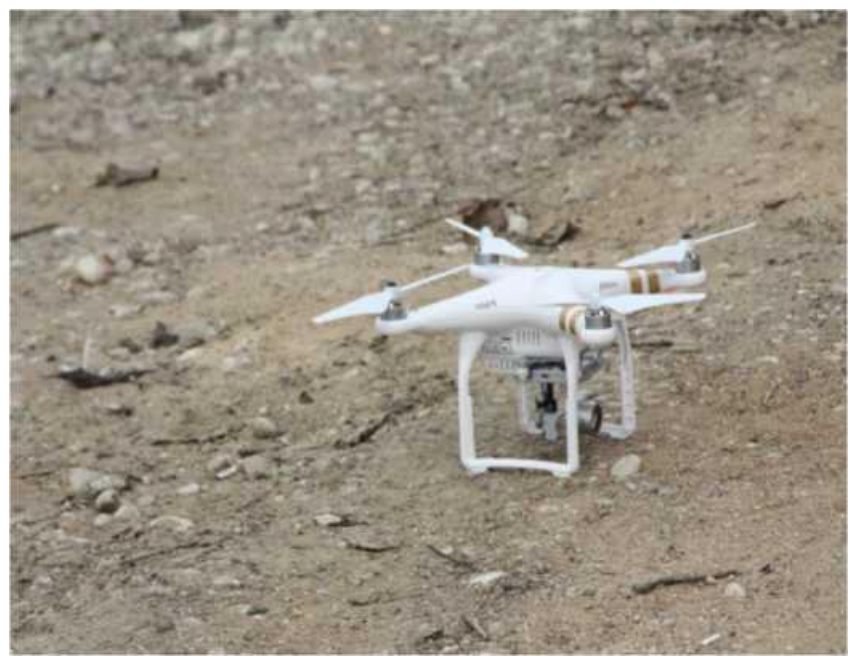

Рисунок 6 - Квадрокоптер модели DJI Phantom 3 Professional

Один из снимков участка разрушаемого берега, полученный с использованием видеокамеры БПЛА, показан на рисунок 7. 


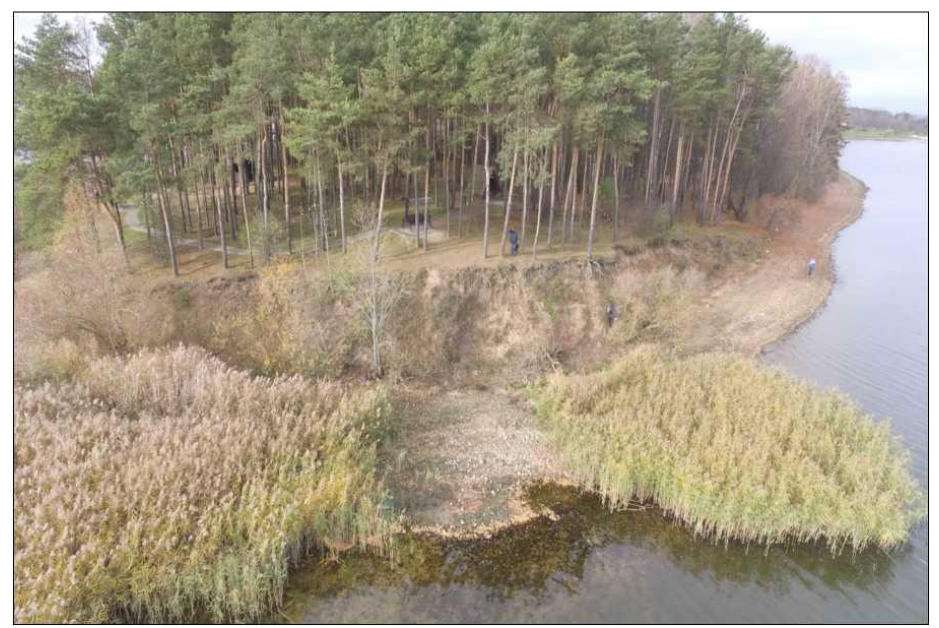

Рисунок 7 - Заславское водохранилище. Юго-западный берег. Участок № 4. Поперечники № 1-3. На переднем плане виден сформированный поток наносов. Высота съемки 50 м

В процессе натурного эксперимента были проведены съемки береговой линии Заславского водохранилища протяженностью более 1500 м, ограждающих дамб и состояния их откосов, польдерной насосной станции и технологического - пруда отстойника, где имеется заложенные сети многолетних стационарных наземных наблюдений.

\section{Заключение}

Полученные фактические экспериментальные данные и материалы съемок позволили заключить следующее:

- регистрация и наблюдение за развитием процесса разрушения естественных берегов водохранилищ и креплений откосов дамб и плотин, равно как других водных объектов (водозаборов, очистных сооружений), с помощью беспилотных радиоуправляемых квадрокоптеров, оснащенных камерами высокого разрешения (4К), возможны и рекомендуются для использования в Беларуси;

- возможно получение материалов с помощью БПЛА, необходимые и достаточно точные измерения линейных деформаций склонов и откосов дамб и плотин, а также их креплений путем установки реперных контрольных реек (марок) с шкалой на участках съемки;

- что очень важно: возможна регистрация параметров склона, а также подводной части водозаборов и очистных сооружений как в надводной, так и подводной частях;

- для оценки влияния водных объектов на прилегающие территории может использоваться комбинированная спутниковая высокого разрешениях, съемка БПЛА и наземная с интеграцией на основе ГИС-систем.

\section{Список цитированных источников}

1. Левкевич, В. Е. Динамическая устойчивость берегов водохранилищ Беларуси / В. Е. Левкевич. - Минск : Право и экономика, 2015. - $307 \mathrm{C}$.

2. Левкевич, В. Е. Динамика береговых процессов русловых, наливных и озерных водохранилищ Беларуси / В. Е. Левкевич. - Минск : Право и экономика, 2015. - 202 с.

3. Левкевич, В. Е. Гидроморфодинамика прибрежной зоны водохранилищ ГЭС Беларуси / В. Е. Левкевич. - Минск : Право и экономика, 2018. - $143 \mathrm{C}$.

4. Левкевич, В. Е. Крепление берегов и верховых откосов подпорных сооружений гидроузлов Беларуси / В. Е. Левкевич. - Минск : БНТУ, 2019. - $172 \mathrm{c}$.

5. Анисимова, Н. А. Динамика переработки береговых склонов Горьковского водохранилища / Н. А. Анисимова, С.В.Тарасова // Наука и техника на речном транспорте : спец. вып. - М., 2003. C. 111-113.

6. Соболь, С. В. Анализ переформирования абразионных берегов Горьковского водохранилища за период 1957-2010 гг. с прогнозом на следующее десятилетие / С. В. Соболь, Л. Б. Иконников, Д. Н. Хохлов // Гидротехническое строительство. - М.; 2011. № 12. - C. 13-20.

7. Соболь, И. С. Модификация метода Е. Г. Качугина для вариантного компьютерного прогноза переформирования абразионных берегов эксплуатируемых равнинных водохранилищ / И. С. Соболь, Д. Н. Хохлов // Вестн. МГСУ. - М., 2012. - № 10: Информационные системы и логистика в строительстве. - С. 281-286.

8. Хабидов, А. Ш. Управление состоянием берегов водохранилищ/ А. Ш. Хабидов [и др.]. - Новосибирск : Изд-во СО РАН, 2009. - 239 с.

9. Назаров, Н. Н. Географическое изучение берегов и акваторий камских водохранилищ / Н. Н. Назаров // Географ. вестн. - 2006. № 2. - C. 18-36.

\section{References}

1. Levkevich, V. E. Dinamicheskaya ustojchivost' beregov vodohranilishch Belarusi / V. E. Levkevich. - Minsk : Pravo i ekonomika, 2015. - 307 s.

2. Levkevich, V. E. Dinamika beregovyh processov ruslovyh, nalivnyh i ozernyh vodohranilishch Belarusi / V. E. Levkevich. - Minsk : Pravo i ekonomika, 2015. - $202 \mathrm{~s}$.

3. Levkevich, V. E. Gidromorfodinamika pribrezhnoj zony vodo-hranilishch GES Belarusi / V. E. Levkevich. - Minsk : Pravo i ekonomika, 2018. $143 \mathrm{~s}$.

4. Levkevich, V. E. Kreplenie beregov i verhovyh otkosov podpornyh sooruzhenij gidrouzlov Belarusi / V. E. Levkevich. - Minsk : BNTU, 2019. - $172 \mathrm{~s}$.

5. Anisimova, N. A. Dinamika pererabotki beregovyh sklonov Gor'kovskogo vodohranilishcha / N. A. Anisimova, S. V. Tarasova // Nauka i tekhnika na rechnom transporte : spec. vyp. - M., 2003. - S. 111-113.

6. Sobol', S. V. Analiz pereformirovaniya abrazionnyh beregov Gor'kovskogo vodohranilishcha za period 1957-2010 gg. s prognozom na sleduyushchee desyatiletie / S. V. Sobol', L. B. Ikonnikov, D. N. Hohlov // Gidrotekhnicheskoe stroitel'stvo. - M.; 2011. - № 12. S. $13-20$

7. Sobol', I. S. Modifikaciya metoda E. G. Kachugina dlya variantnogo komp'yuternogo prognoza pereformirovaniya abrazionnyh beregov ekspluatiruemyh ravninnyh vodohranilishch / I. S. Sobol', D. N. Hohlov // Vestn. MGSU. - M., 2012. - № 10: Informacionnye sistemy i logistika v stroitel'stve. - S. 281-286.

8. Habidov, A. SH. Upravlenie sostoyaniem beregov vodohranilishch / A. SH. Habidov [i dr.]. - Novosibirsk : Izd-vo SO RAN, 2009. - 239 s.

9. Nazarov, N. N. Geograficheskoe izuchenie beregov i akvatorij kamskih vodohranilishch / N. N. Nazarov // Geograf. vestn. - 2006. № 2. - S. 18-36.

Материал поступил в редакцию 14.04.2020 